\title{
Cardiomyopathy in patients with Marfan syndrome and marfanoid habitus
}

\author{
Ekaterina Luneva MD, PhD ${ }^{1}$, Eduard Malev MD, PhD ${ }^{1,2}$, Alexandra Korshunova MD ${ }^{1,2}$, Svetlana Reeva MD PhD ${ }^{1,2}$, Eugeniy Timofeev MD PhD ${ }^{1,2}$ and \\ Eduard Zemtsovsky Prof MD PhD ${ }^{1,2}$
}

Lunev E, Malev E, Korshunova A, et al. Cardiomyopathy in patients with Marfan syndrome and marfanoid habitus. Curr Res Cardiol 2017;4(1): 9-13.

OBJECTIVES: The term "Marfan cardiomyopathy" is used to indicate changes in left ventricular function in the absence of significant valvular pathology in Marfan syndrome. It is still unknown if there are any changes in cardiac function in patients with similar connective tissue abnormality such as marfanoid habitus.

METHODS: In the study were included 98 persons - 8 patients with Marfan syndrome, 24 with marfanoid habitus and 66 healthy subjects. Echocardiography was performed to all patients. Speckle tracking echocardiography was used to assess the left ventricular deformation indices. Concentrations of transforming growth factor $-\beta 1$ and $-\beta 2$ in serum were determined by enzyme-linked immunosorbent assay.

RESULTS: Systolic left ventricular function was significantly lower in the Marfan syndrome group; as well global longitudinal left ventricular strain worsening was detected in MS group comparing to control group. In marfanoid habitus subjects, we found significant decrease of the circumferential strain in the interventricular septum and inferior wall. transforming growth factor- $\beta 1$ and $-\beta 2$ serum levels were elevated in patients with Marfan syndrome. Elevation of transforming growth factor- $\beta 1$ was statistically nonsignificant unlike to transforming growth factor $\beta 2$ in the marfanoid habitus group. Negative correlations between the serum level of transforming growth factor- $\beta 2$ and systolic radial strain in the marfanoid habitus group also have been found.

CONCLUSION: Worsening of regional myocardial deformation may be the first sign of deterioration of the left ventricular systolic function and the existence of primary cardiomyopathy in asymptomatic marfanoid habitus patients, which could affect their long-term prognosis and may be caused by increased transforming growth factor- $\beta$ signaling.

Key Words: Marfan syndrome; Marfanoid habitus; Cardiomyopathy; Left ventricular systolic function; Myocardial deformation; Transforming growth factor- $\beta$
MS is one of the most common heritable disorder of connective tissue. In the range of MS complications are aortic aneurism, mitral valve prolapses and myocardial dysfunction (1). MS manifestations caused by mutations of fibrillin-1, a structural component of extracellular matrix, and also violation of the regulation of transforming growth factor- $\beta$. A number of studies $(2,3)$ showed that excessive activation of TGF- $\beta$ signaling pathway is the main reason of the impairment of LV function and aorta pathology in MS. Deterioration of systolic and diastolic function and enlargement of LV dimensions was found in patients with MS regardless the absence of hemodynamic overload due to mitral or aortic regurgitation in presence of mitral valve prolapse or aortic dilatation. The term "Marfan cardiomyopathy" is used to indicate changes in left ventricular function in the absence of significant valvular pathology in MS (4,5). In spite the fact that cardiomyopathy in MS is well studied it is still unknown if there are changes in the cardiac function in patients with similar connective tissue abnormality such as marfanoid habitus. marfanoid habitus includes arachnodactyly, long hands and feet, increased skin stretch, joint hypermobility and changes in the physiology of the pectus (Table 1).

\section{TABLE 1}

\section{Marfanoid habitus criteria}

\begin{tabular}{|c|c|}
\hline Measurable skeletal signs & Other features of the marfanoid habitus \\
\hline - Arm span to height ratio $>1.03$ & - Scoliosis of $>5$ degrees \\
\hline - Hand length to height ratio $>11 \%$ & $\begin{array}{l}\text { - Pectus deformities (excavatum or } \\
\text { carinatum) }\end{array}$ \\
\hline - Foot length to height ratio $>15 \%$ & - Jaw deformities with overcrowding of teeth \\
\hline \multirow[t]{2}{*}{$\begin{array}{l}\text { - Upper body segment to lower } \\
\text { body segment ratio }<0.89\end{array}$} & - High-arched palate \\
\hline & $\begin{array}{l}\text { - Long feet (often with hammer toes) that } \\
\text { flatten and pronate on weight-bearing }\end{array}$ \\
\hline
\end{tabular}

Marfanoid features are present in several heritable disorders of connective tissue, mimicking some of the changes of Marfan syndrome but not accompanied by luxation of lens, and aneurysm of aorta. Incomplete forms of the marfanoid habitus are commonplace and likely to be benign; however, their presence should trigger an assessment for another feature of heritable disorders of connective tissue (6).

In this paper, we evaluated the morphological and functional characteristics of the LV in patients with MS and marfanoid habitus.

\section{MATERIALS AND METHODS}

In the study were included 98 persons, 8 of them were patients with MS, 24 patients with marfanoid habitus and 66 healthy subjects.

Patients with MS were under regular follow-up at Almazov Federal Centre. The diagnosis of MS was made applying Ghent criteria (7). Mutations of fibrillin-1 didn't screen for this study. Patients did not have significant (more than mild) mitral or aortic regurgitation. Subjects with marfanoid habitus were screened out of patients with non-confirmed MS and have no signs of aortic aneurism and lens subluxation. Table 1 represents marfanoid habitus criteria according to Grahame R, et al. (6). Control group consisted of healthy students of Pediatric Medical University.

Echocardiography was performed in all patients by an experienced echocardiographer using a Vivid 7 ultrasound system (GE Healthcare), equipped with a harmonic $3.5 \mathrm{~Hz}$ phased-array transducer and included assessment of heart chambers dimensions, and systolic function of LV measured by Simpson biplane rule. Standard 2-dimensional transthoracic echocardiographic recordings were used to assess left ventricular as LV enddiastolic diameter, to assess right ventricle as right ventricle end-diastolic diameter, for left atria we used left artia diameter according to current guideline (8). Additionally, we used speckle tracking echocardiography to assess the left ventricular deformation indices (strain and strain rate)

${ }^{1}$ Department of connective tissue disorders, Almazov North-West Federal Medical Research Centre, Saint-Petersburg, Russia; ${ }^{2}$ Department of propaedeutics of internal diseases, State Pediatric Medical University, Saint-Petersburg, Russia

Correspondence: Dr. Ekaterina Luneva, MD, PhD, Almazov North-West Federal Medical Research Centre, 2 Akkuratova str., Saint-Petersburg, 197341, Russia, Telephone +7-8127023749; Fax:+7-8127023744, Email e.luneva@hotmail.com

Received: December 29, 2016, Accepted: March 17, 2017, Published: March 20, 2017 
(9). The longitudinal strain is obtained from apical 4-, 3- and 2-chamber images. Radial and circumferential strains were obtained from LV shortaxis images at the level of the mitral valve, papillary muscles and apex. Image analysis was performed offline on an EchoPAC'08 workstation (GE Healthcare). The LV was divided into 18 segments. Strain rate was determined as the maximal negative value during the ejection phase. Peak systolic strain was defined as the magnitude of strain at the aortic valve closure. The peak longitudinal early diastolic filling strain rate was also measured.

We assess biologically active transforming growth factor $\beta 1$ and $-\beta 2$ protein concentrations from EDTA blood samples using standard procedures by enzyme-linked immunosorbent assays using the Human Platinum ELISA test system (Bender MedSysteMarfan syndrome Diagnostics GmbH, Vienna, Austria). The inter-assay and intra-assay variations were $8 \%$ and $6 \%$, respectively. The sensitivity was $5 \mathrm{pg} / \mathrm{ml}$.

\section{STATISTICAL ANALYSIS}

All data are presented as mean \pm standard deviation. The significance of differences between quantitative traits was determined using Student's t-test, between small samples and qualitative characteristics determined using the non-parametric methods: Fisher's exact test or chi-square test $(p<0.05)$. The relationship between pairs of continuous variables was expressed by the Pearson correlation. Effect sizes for deformation indices were measured by Cohen's d using means and standard deviations. Statistical significance was set at $p<0.05$. All statistical analyses were performed using Statistica 10 software (StatSoft, Inc.).

\section{TABLE 2}

\section{Characteristics of patients included in the study}

\begin{tabular}{|c|c|c|c|c|}
\hline & $\begin{array}{c}\text { Marfan } \\
\text { syndrome } \\
(n=8)\end{array}$ & $\begin{array}{c}\text { Marfanoid } \\
\text { habitus } \\
(n=24)\end{array}$ & $\begin{array}{l}\text { Control } \\
\text { group } \\
(n=66)\end{array}$ & $\begin{array}{l}\mathrm{p} \text { (Student's t-test, } \\
\text { Fisher's exact test) }\end{array}$ \\
\hline \multirow{3}{*}{ Sex, female/male } & \multirow{3}{*}{$0 / 8$} & \multirow{3}{*}{ Jan-23 } & \multirow{3}{*}{$42 / 24$} & $(1-2) p=0.55$ \\
\hline & & & & $(1-3) p=0.0006$ \\
\hline & & & & $(2-3) p=0.00001$ \\
\hline \multirow{3}{*}{ Age, years } & \multirow{3}{*}{$28 \pm 9.2$} & \multirow{3}{*}{$22 \pm 3.4$} & \multirow{3}{*}{$20 \pm 1.8$} & $(1-2) 0.01$ \\
\hline & & & & (1-3) 0.0001 \\
\hline & & & & (2-3) 0.0005 \\
\hline \multirow{3}{*}{ Height, m } & \multirow{3}{*}{$186 \pm 12$} & \multirow{3}{*}{$181 \pm 9.1$} & \multirow{3}{*}{$170 \pm 8.4$} & $(1-2) 0.22$ \\
\hline & & & & (1-3) 0.00001 \\
\hline & & & & (2-3) 0.00001 \\
\hline \multirow{3}{*}{ Weight, kg } & \multirow{3}{*}{$71 \pm 26$} & \multirow{3}{*}{$62 \pm 9.7$} & \multirow{3}{*}{$61 \pm 9.5$} & $(1-2) 0.16$ \\
\hline & & & & $(1-3) 0.03$ \\
\hline & & & & $(2-3) 0.66$ \\
\hline \multicolumn{5}{|c|}{ Marfan syndrome criteria } \\
\hline \multirow{3}{*}{$\begin{array}{c}\text { Aortic diameter } \\
\text { at the sinuses of } \\
\text { Valsalva above } \\
\text { Z-score } 2 \text { or aortic } \\
\text { root dissection, } \\
\mathrm{n}(\%)\end{array}$} & \multirow[b]{3}{*}{$5(63 \%)$} & \multirow[b]{3}{*}{$0(0 \%)$} & \multirow[b]{3}{*}{$0(0 \%)$} & $(1-2) 0.008$ \\
\hline & & & & $(1-3) 0.008$ \\
\hline & & & & $(2-3) 1.0$ \\
\hline \multirow{3}{*}{$\begin{array}{c}\text { Ectopia lentis, } \\
\mathrm{n}(\%)\end{array}$} & \multirow{3}{*}{$3(38 \%)$} & \multirow{3}{*}{$0(0 \%)$} & \multirow{3}{*}{$0(0 \%)$} & $(1-2) 0.065$ \\
\hline & & & & (1-3) 0.065 \\
\hline & & & & $(2-3) 1.0$ \\
\hline \multicolumn{5}{|c|}{ Scoring of systemic features of the Marfan syndrome } \\
\hline \multirow{3}{*}{$\begin{array}{l}\text { Wrist AND thumb } \\
\text { sign, } \mathrm{n}(\%)\end{array}$} & \multirow{3}{*}{$4(50 \%)$} & \multirow{3}{*}{$8(33 \%)$} & & $(1-2) 0.41$ \\
\hline & & & $0(0 \%)$ & $(1-3) 0.025$ \\
\hline & & & & $(2-3) 0.002$ \\
\hline & & & & $(1-2) 0.38$ \\
\hline sign, $\mathrm{n}(\%)$ & $7(88 \%)$ & $16(67 \%)$ & $0(0 \%)$ & $(1-3) 0.0002$ \\
\hline & & & & $(2-3)<0.00001$ \\
\hline$P$ & & & & $(1-2) 0.18$ \\
\hline deformity $n(\%)$ & $7(88 \%)$ & $3(13 \%)$ & $0(0 \%)$ & $(1-3) 0.0003$ \\
\hline & & & & $(2-3)<0.00001$ \\
\hline Pectus excavatum & & & & $(1-2) 0.41$ \\
\hline or chest & $4(50 \%)$ & $16(67 \%)$ & $0(0 \%)$ & (1-3) 0.025 \\
\hline asymmetry, n (\%) & & & & $(2-3)<0.00001$ \\
\hline Hindfoot deformity & & & & $(1-2) 0.5296$ \\
\hline or plain pes planus, & $5(63 \%)$ & $18(75 \%)$ & $7(11 \%)$ & $(1-3) 0.0166$ \\
\hline $\mathrm{n}(\%$ & & & & $(2-3)<0.00001$ \\
\hline
\end{tabular}

\begin{tabular}{|c|c|c|c|c|}
\hline \multirow{3}{*}{$\begin{array}{c}\text { Pneumothorax, } \\
\mathrm{n}(\%)\end{array}$} & \multirow{3}{*}{$0(0 \%)$} & \multirow{3}{*}{$1(4 \%)$} & \multirow{3}{*}{$0(0 \%)$} & (1-2) 1.0 \\
\hline & & & & (1-3) 1.0 \\
\hline & & & & (2-3) 0.27 \\
\hline \multirow{3}{*}{$\begin{array}{c}\text { Dural ectasia, } \mathrm{n} \\
(\%)\end{array}$} & \multirow{3}{*}{$0(0 \%)$} & \multirow{3}{*}{$0(0 \%)$} & \multirow{3}{*}{$0(0 \%)$} & $(1-2) 1.0$ \\
\hline & & & & (1-3) 1.0 \\
\hline & & & & (2-3) 1.0 \\
\hline \multirow{3}{*}{$\begin{array}{c}\text { Protrusio acetabuli, } \\
\mathrm{n}(\%)\end{array}$} & \multirow{3}{*}{$0(0 \%)$} & \multirow{3}{*}{$0(0 \%)$} & \multirow{3}{*}{$0(0 \%)$} & $(1-2) 1.0$ \\
\hline & & & & (1-3) 1.0 \\
\hline & & & & (2-3) 1.0 \\
\hline \multirow{3}{*}{$\begin{array}{c}\text { Reduced US/LS } \\
\text { AND increased } \\
\text { arm/height AND no } \\
\text { severe scoliosis, } \\
n(\%)^{*}\end{array}$} & \multirow{3}{*}{$2(25 \%)$} & \multirow{3}{*}{$0(0 \%)$} & \multirow{3}{*}{$0(0 \%)$} & $(1-2) 0.15$ \\
\hline & & & & (1-3) 0.15 \\
\hline & & & & (2-3) 1.0 \\
\hline \multirow{3}{*}{$\begin{array}{l}\text { Scoliosis or } \\
\text { thoracolumbar } \\
\text { kyphosis, n (\%) }\end{array}$} & \multirow{3}{*}{$7(88 \%)$} & \multirow{3}{*}{$23(96 \%)$} & \multirow{3}{*}{$20(30 \%)$} & $(1-2) 0.54$ \\
\hline & & & & (1-3) 0.0016 \\
\hline & & & & $(2-3)<0.00001$ \\
\hline \multirow{3}{*}{$\begin{array}{l}\text { Reduced elbow } \\
\text { extension, } \mathrm{n}(\%)\end{array}$} & \multirow{3}{*}{$1(13 \%)$} & \multirow{3}{*}{$0(0 \%)$} & \multirow{3}{*}{$0(0 \%)$} & $(1-2) 1,0$ \\
\hline & & & & $(1-3) 1,0$ \\
\hline & & & & (2-3) 1.0 \\
\hline \multirow{3}{*}{$\begin{array}{l}\text { Facial features } \\
(3 / 5)^{\star \star}, \mathrm{n}(\%)\end{array}$} & \multirow{3}{*}{$6(75 \%)$} & & & $(1-2) 0.15$ \\
\hline & & $1(4 \%)$ & $0(0 \%)$ & (1-3) 0.0018 \\
\hline & & & & (2-3) 1.0 \\
\hline & & & & (1-2) 1.0 \\
\hline Skin striae, $\mathrm{n}(\%)$ & $0(0 \%)$ & $1(4 \%)$ & $0(0 \%)$ & $(1-3) 1.0$ \\
\hline & & & & (2-3) 1.0 \\
\hline & & & & $(1-2) 0.69$ \\
\hline $\begin{array}{c}\text { Myopia > } 3 \\
\end{array}$ & $4(50 \%)$ & $10(42 \%)$ & $8(12 \%)$ & (1-3) 0.066 \\
\hline & & & & (2-3) 0.011 \\
\hline Mitral vaLVe & & & & $(1-2) 0.65$ \\
\hline prolapse (all & $2(25 \%)$ & $8(33 \%)$ & $0(0 \%)$ & $(1-3) 0.15$ \\
\hline types), n (\%) & & & & (2-3) 0.002 \\
\hline & & & & $(1-2) 0.0002$ \\
\hline $\begin{array}{l}\text { Systemic features } \\
\text { score, points }\end{array}$ & $8,1 \pm 1,2$ & $5,4 \pm 1,6$ & $2,1 \pm 0,5$ & $(1-3)<0.00001$ \\
\hline & & & & $(2-3)<0.00001$ \\
\hline & Marfa & id habitus c & iteria*** & \\
\hline & & & & $(1-2) 0.41$ \\
\hline $\begin{array}{l}\text { Skeletal signs of } \\
\text { marfanoid habitus }\end{array}$ & $5(63 \%)$ & $19(79 \%)$ & $5(8 \%)$ & $(1-3) n / a$ \\
\hline & & & & $(2-3)<0.00001$ \\
\hline Jaw deformities & & & & (1-2) 0.84 \\
\hline with overcrowding & $5(63 \%)$ & $14(58 \%)$ & $16(24 \%)$ & (1-3) 0.07 \\
\hline of teeth & & & & (2-3) 0.005 \\
\hline High-arched palate & $7(88 \%)$ & $12(50 \%)$ & $8(12 \%)$ & (1-2) 0.028 \\
\hline mign-arcrea palate & $1(00 \%)$ & & & $(1-3) 0.0004$ \\
\hline
\end{tabular}

*The combined presence of reduced upper segment to lower segment (US/LS) ratio (for adults $<0.85$ ) and increased arm span to height ratio (for adults $>1.05$ ) in the absence of significant scoliosis

**Dolichocephaly, enophthalmos, downslanting palpebral fissures, malar hypoplasia, retrognathia

***For scoliosis, pectus deformities and long feet see the scoring of systemic features of the Marfan syndrome.

\section{RESULTS}

Characteristics of patients included in the study are shown in Table 2.

In groups with MS and marfanoid habitus men were predominated. Patients with MS were older than those with marfanoid habitus and individuals from control group. Patients with MS were taller than others. Systemic features were significantly often found in patients with MS comparing to marfanoid habitus. Systemic features score allowed distinguishing MS patient from marfanoid habitus patients. On the other side marfanoid habitus criteria were found in both MS and marfanoid habitus patients but allowed separate marfanoid habitus from healthy individuals. Thus, presence of skeletal signs in absence of other Ghent criteria allows verifying marfanoid habitus with high sensitivity $(79 \%)$ and specificity (91\%).

The results of morphological and functional evaluation of heart were summarized in Table 3.

There was no statistically significant difference in size of the right ventricle 
and left atrium in young patients in control group comparing with marfanoid habitus patients but expectably these dimensions statistically differ in patients of MS group. However, left ventricular enlargement was found not

\section{TABLE 3}

\section{Echocardiographic data in study groups}

\begin{tabular}{|c|c|c|c|c|}
\hline & $\begin{array}{l}\text { Marfan } \\
\text { syndrome } \\
(n=8)\end{array}$ & $\begin{array}{c}\text { Marfanoid } \\
\text { habitus }(n=24)\end{array}$ & $\begin{array}{c}\text { Control } \\
\text { group }(n=66)\end{array}$ & $\begin{array}{l}\text { p (Student's } \\
\text { t-test, Fisher's } \\
\text { exact test) }\end{array}$ \\
\hline \multirow{3}{*}{$\begin{array}{l}\text { End-diastolic } \\
\text { LV diameter, } \\
\mathrm{mm}\end{array}$} & \multirow{3}{*}{$50.5 \pm 4.6$} & \multirow{3}{*}{$46.7 \pm 4.54$} & \multirow{3}{*}{$44.1 \pm 4.94$} & $(1-2) 0.012$ \\
\hline & & & & (1-3) 0.0003 \\
\hline & & & & $(2-3) 0.027$ \\
\hline \multirow{3}{*}{$\begin{array}{l}\text { End-systolic } \\
\text { LV diameter, } \\
\mathrm{mm}\end{array}$} & \multirow{3}{*}{$34.8 \pm 3.8$} & \multirow{3}{*}{$29.5 \pm 4.9$} & \multirow{3}{*}{$28.4 \pm 3.9$} & $(1-2) 0.005$ \\
\hline & & & & (1-3) 0.0014 \\
\hline & & & & $(2-3) 0.33$ \\
\hline \multirow{3}{*}{$\begin{array}{l}\text { End-diastolic } \\
\text { LV volume } \\
\text { mm }\end{array}$} & \multirow{3}{*}{$114.3 \pm 12.6$} & \multirow{3}{*}{$98.7 \pm 19.2$} & \multirow{3}{*}{$89.3 \pm 19.2$} & (1-2) 0.019 \\
\hline & & & & (1-3) 0.0002 \\
\hline & & & & (2-3) 0.046 \\
\hline \multirow{3}{*}{$\begin{array}{c}\text { End-systolic } \\
\text { LV volume, } \\
\text { mm }\end{array}$} & \multirow{3}{*}{$55.2 \pm 14.0$} & \multirow{3}{*}{$33.9 \pm 12.6$} & \multirow{3}{*}{$33.9 \pm 8.9$} & $(1-2) 0.0028$ \\
\hline & & & & (1-3) 0.0026 \\
\hline & & & & $(2-3) 1.0$ \\
\hline \multirow{3}{*}{$\begin{array}{l}\text { Ejection } \\
\text { fraction, \% }\end{array}$} & \multirow{3}{*}{$52.8 \pm 8.9$} & \multirow{3}{*}{$66.4 \pm 7.5$} & \multirow{3}{*}{$67 \pm 5.3$} & (1-2) 0.0003 \\
\hline & & & & (1-3) 0.00001 \\
\hline & & & & $(2-3) 0.48$ \\
\hline \multirow{3}{*}{$\begin{array}{c}\text { Left } \\
\text { ventricular } \\
\text { mass index, } \\
\mathrm{g} / \mathrm{m}^{2}\end{array}$} & \multirow{3}{*}{$111.8 \pm 31.5$} & \multirow{3}{*}{$78.5 \pm 18.9$} & \multirow{3}{*}{$83.7 \pm 15.9$} & (1-2) 0.027 \\
\hline & & & & $(1-3) 0.033$ \\
\hline & & & & $(2-3) 0.23$ \\
\hline \multirow{3}{*}{ E/A ratio } & \multirow{3}{*}{$1.50 \pm 0.47$} & \multirow{3}{*}{$1.53 \pm 0.42$} & \multirow{3}{*}{$1.69 \pm 0.4$} & $(1-2) 0.87$ \\
\hline & & & & $(1-3) 0.10$ \\
\hline & & & & (2-3) 0.48 \\
\hline End-diastolic & & & & (1-2) 0.0006 \\
\hline diameter of & $31 \pm 7.2$ & $23 \pm 4.26$ & $24 \pm 3.13$ & $(1-3) 0.00001$ \\
\hline 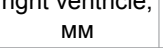 & & & & $(2-3) 0.23$ \\
\hline & & & & $(1-2) 0.0003$ \\
\hline $\begin{array}{l}\text { Diameter of } \\
\text { left atrium }\end{array}$ & $37 \pm 4.97$ & $30 \pm 3.98$ & $30 \pm 2.99$ & 0.00001 \\
\hline & & & & $(2-3) 1.0$ \\
\hline Aortic & & & & (1-2) 0.0007 \\
\hline diameter at & $43.1 \pm 15.1$ & $30.3 \pm 4.5$ & $24.0 \pm 4.5$ & $(1-3) 0.00001$ \\
\hline Valsalva, mm & & & & (2-3) 0.00001 \\
\hline & & & & $(1-2) 0.039$ \\
\hline Z-score & $6.86 \pm 5.83$ & $1.56 \pm 0.93$ & $1.59 \pm 0.17$ & $(1-3) 0.038$ \\
\hline & & & & $(2-3) 0.88$ \\
\hline Mitral & & & & $(1-2) 0.29$ \\
\hline $\begin{array}{l}\text { regurgitation } \\
\text { grade, none/ }\end{array}$ & $0 / 8(0 / 100 \%)$ & $6 / 18(25 / 75 \%)$ & $\begin{array}{c}24 / 42 \\
(36 / 64 \%)\end{array}$ & $(1-3) 0.047$ \\
\hline mild (\%) & & & & (2-3) 0.44 \\
\hline
\end{tabular}

only in patients with MS but also in marfanoid habitus patients comparing with control group but it should be noted that the dimensions of the LV were normal in all groups of observation.

As expected, systolic LV function was significantly lower in the MS group, but there were no statistically significant differences in left ventricular EF between patients with marfanoid habitus and control group. As well global longitudinal left ventricular strain worsening was detected in MS group (strain: $-15,7 \pm 0,9 \%$ vs. $-19,6 \pm 3,4 \%, p=0,002$; strain rate: $-0,94 \pm 0,09$ $\mathrm{s}-1$ vs. $-1,22 \pm 0,18 \mathrm{~s}-1, \mathrm{p}=0,00001)$. At the same time, no changes in global longitudinal, circumferential or radial strain/strain rate were found in marfanoid habitus patients (Table 4).

To reveal subtle changes in LV contractility in marfanoid habitus patients the speckle tracking analysis was used to assess regional strain of the LV walls (Table 4). We found significant decrease of the circumferential (otherwise to longitudinal or radial) strain in the interventricular septum and inferior wall in marfanoid habitus subjects (Figure 1) comparing to control group, with medium effect sizes measured by Cohen's d $(0.53-0.66)$. In other LV walls no significant difference was found. Diastolic function was preserved in all study groups.

TGF- $\beta 1$ and TGF- $\beta 2$ serum levels were elevated in patients with marfanoid habitus $(14.2 \pm 27.6$ and $2.1 \pm 1.7 \mathrm{ng} / \mathrm{ml}$, respectively) and in spite to considerable standard deviation we found significant difference with MS
TABLE 4

Global and local strain and strain rate in marfanoid habitus and control groups

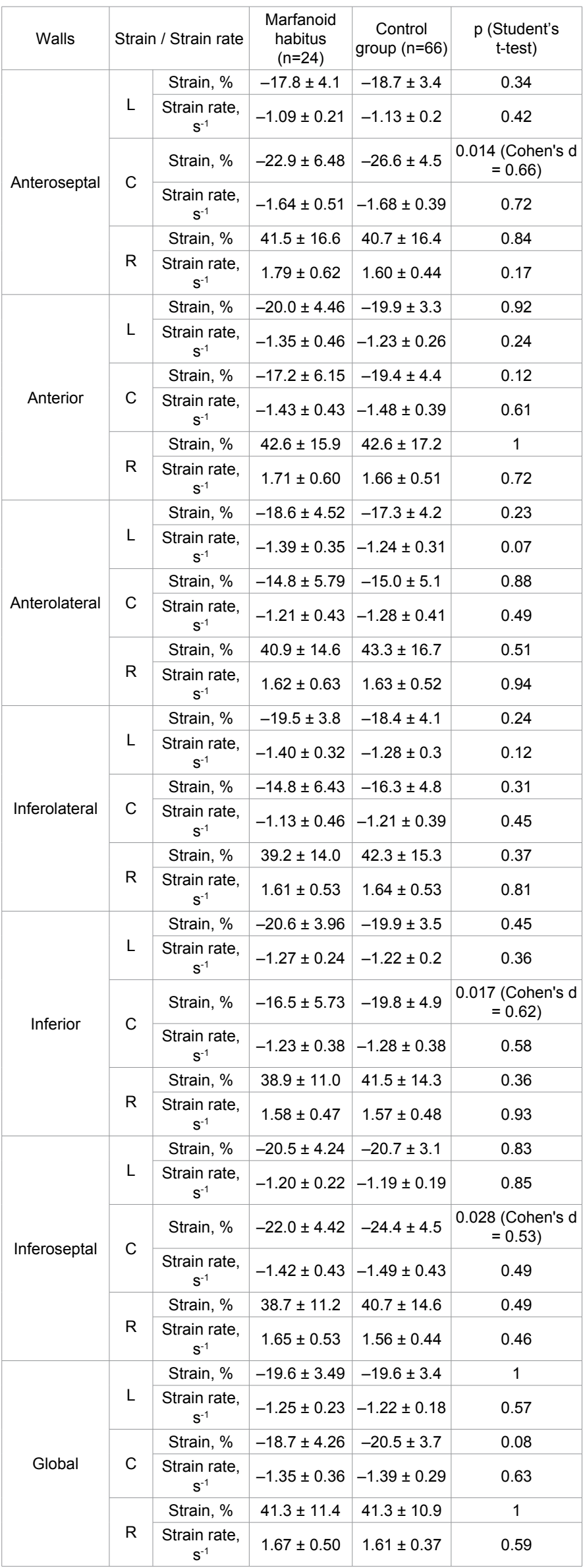

L - Longitudinal, C - Circumferential, $R$ - Radial. 


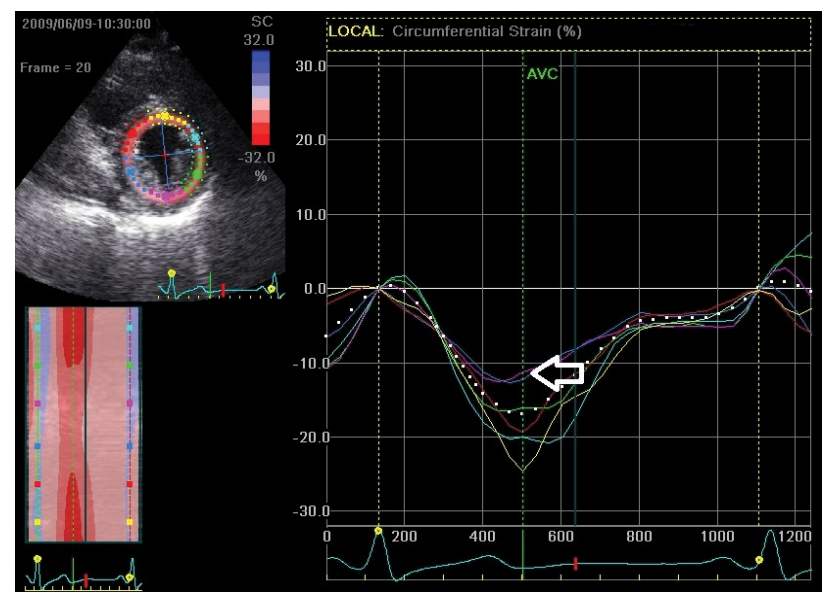

Figure 1) Low circumferential strain in inferior wall (arrow) in marfanoid habitus patients
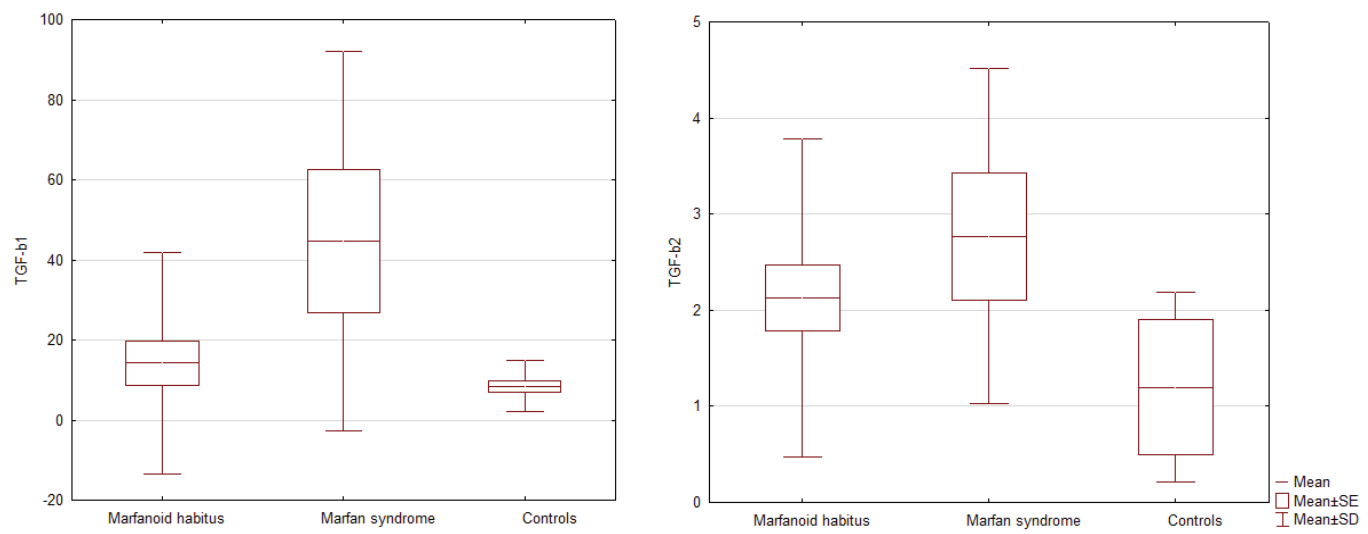

Figure 2) TGF- $\beta 1$ and $\beta 2$ levels in study groups

$(44.6 \pm 47.3 \mathrm{ng} / \mathrm{ml}, \mathrm{p}=0.03$ and $2.7 \pm 1.7 \mathrm{ng} / \mathrm{ml}, \mathrm{p}=0.39$, respectively $)$, and $\operatorname{control}(8.4 \pm 3.5 \mathrm{ng} / \mathrm{ml}, \mathrm{p}=0.09$ and $1.2 \pm 0.7 \mathrm{ng} / \mathrm{ml}, \mathrm{p}=0.0006$, respectively) groups (Figure 2).

A high TGF- $\beta 1$ serum level $(>14.75 \mathrm{ng} / \mathrm{ml})$ was detected in the half of the group and TGF- $\beta 2(>2.0 \mathrm{ng} / \mathrm{ml})$ in majority patients $(75 \%)$ of the MS group. In marfanoid habitus group we found a high TGF- $\beta 1$ serum level in $4(17 \%)$ patients and TGF- $\beta 2$ in $9(38 \%)$ patients that is more than in control group. In control group there were no individuals with elevated levels of TGF- $\beta 1$ and only 2 persons with high TGF- $\beta 2$ level.

Additionally, we have identified the negative correlations between the serum level of transforming growth factor $\beta 2$ and systolic radial strain $(\mathrm{r}=0.53$, $\mathrm{p}=0.012$ ) in the marfanoid habitus group. There was no correlation between TGF- $\beta$ level and aortic dimensions in patients with MS and marfanoid habitus; but was found correlation between TGF- $\beta$ level and skeletal features of the marfanoid habitus - TGF- $\beta 2$ with foot length-to-height ratio $(\mathrm{r}=0.47$, $\mathrm{p}=0.03)$, TGF- $\beta 1$ with scoliosis $(\mathrm{r}=0.72, \mathrm{p}=0.0001)$. TGF- $\beta 1$ serum level also weakly correlated with end diastolic volume $(\mathrm{r}=0.42, \mathrm{p}=0.04)$ and LV myocardial mass $(\mathrm{r}=0.44, \mathrm{p}=0.036)$.

\section{DISCUSSION}

Lowering of LV global contractility in patients with MS has been described previously in several studies $(4,5)$. In our study we also found deterioration of LV global contractility and deformation in normal LV dimensions in patients with MS. In patients with marfanoid habitus LV systolic function was preserved and only decrease of the circumferential (otherwise to longitudinal or radial) strain in the interventricular septum and inferior wall was found.

The marfanoid habitus is an important common feature in a number of genetically heritable disorders of connective tissue syndromes and isn't pathognomonic of MS (6). Current Ghent and marfanoid habitus criteria $(6,7)$ allow to distinguishing MS patient from marfanoid habitus patients in our study with high sensitivity and specificity. The most important finding of the present investigation was that the early contractile injury seen in marfanoid habitus patients with normal global contractile function is regionally distributed in the LV septum and inferior wall. To our knowledge, this is the first reported finding of such a regional contractile pattern demonstrated in patients with marfanoid habitus. Several studies demonstrated regional contractile dysfunction in other heritable disorders of connective tissue such as mitral valve prolapse $(10,11)$. In some genetic diseases such as Friedreich's ataxia, Fabry disease, or Duchenne cardiomyopathy, the first regional deformation changes also occur in the inferolateral segment (12).

Currently, there are data indicating that impairment of heart function in the MS and similar phenotypic syndromes has a similar character TGF- $\beta$ dysregulation (13). Mechanism of heart affection in these types of diseases is the left ventricular wall remodeling due to an increased activation of TGF- $\beta$ signaling pathway. Huntgeburt et al. (14) demonstrate that TGF- $\beta$ regulates the hypertrophic and contractile response to $\beta$-adrenergic stimulation in the heart, leading to cardiac hypertrophy and myocardial dysfunction. Circulating TGF- $\beta$ has received attention because it may potentially serve as a biomarker for of aortic remodeling progression in patients not only with MS but also in other genetic aortic syndromes $(15,16)$. Besides marked elevation of TGF- $\beta$ level in patients with MS in our study for the first time have been showing the significant elevation of transforming growth factor- $\beta 1$ and $-\beta 2$ serum levels in marfanoid habitus patients, that can contribute to subclinical myocardial involvement - decrease in regional left ventricular systolic function.

\section{LIMITATIONS OF THE STUDY}

Our study has several limitations. A number of participants in different groups not equal. Due to a rare pathology as Marfan syndrome it is impossible to achieve an equal number of participants in study and control group. The populations are unmatched for age and gender because we included participants in the study consecutively. Mutations of fibrillin-1 didn't screen for this study.

\section{CONCLUSION}

Deterioration of regional contractility in young people with heritable connective tissue disorders occurs not only in individuals with Marfan syndrome, but also in subjects with marfanoid habitus who has allegedly only skeletal features without cardiovascular manifestations. Worsening of regional myocardial deformation may be the first sign of deterioration of the 
left ventricular systolic function and the existence of primary cardiomyopathy in asymptomatic marfanoid habitus patients, which could affect their longterm prognosis (17) and may be caused by increased TGF- $\beta$ signaling. It is hoped that with future advances in exome scanning and other innovations in molecular genetics, it will soon be possible to reveal the genetic basis of marfanoid habitus (6).

\section{CONFLICT OF INTEREST}

No conflict of interest among the authors.

\section{REFERENCES}

1. Pyeritz RE. The Marfan syndrome. Annu Rev Med 2000;51:481-10.

2. Carta L, Pereira L, Arteaga-Solis E, et al. Fibrillins 1 and 2 perform partially overlapping functions during aortic development. J Biol Chem 2006;281:8016-23.

3. Habashi JP, Judge DP, Holm TM, et al. Losartan, an AT1 antagonist, prevents aortic aneurysm in a mouse model of Marfan syndrome. Science 2006;312:117-21.

4. Alpendurada F, Wong J, Kiotsekoglou A, et al. Evidence for Marfan cardiomyopathy. Eur J Heart Fail 2010;12:1085-91.

5. Hetzer R, Siegel G, Delmo-Walter EM. Cardiomyopathy in Marfan syndrome. Eur J Cardiothorac Surg 2016;49:561-67.

6. Grahame R, Hakim AJ. Arachnodactyly-a key to diagnosing heritable disorders of connective tissue. Nat Rev Rheumatol 2013;9:358-64.

7. Loeys BL, Dietz HD, Braverman AC, et al. The revised Ghent nosology for the Marfan syndrome. J Med Genet 2010;47:476-85.

8. Lang R, Badano L, Afilalo J, et al. Recommendations for Cardiac Chamber Quantification by Echocardiography in Adults: An Update from the American Society of Echocardiography and the European
Association of Cardiovascular Imaging. Eur Heart J Cardiovasc Imaging 2015;16:233-71.

9. Voigt JU, Pedrizzetti G, Lysyansky P, et al. Definitions for a common standard for 2D speckle tracking echocardiography: consensus document of the EACVI/ASE/Industry Task Force to standardize deformation imaging. Eur Heart J Cardiovasc Imaging 2015;16:1-11.

10. Malev E, Reeva S, Vasina L, et al. Cardiomyopathy in young adults with classic mitral valve prolapse. Cardiol Young 2014;24:694-01.

11. Maniar HS, Brady BD, Lee U, et al. Early left ventricular regional contractile impairment in chronic mitral regurgitation occurs in a consistent, heterogeneous pattern. J Thorac Cardiovasc Surg 2014;148:1694-9.

12. Bijnens BH, Cikes M, Claus $\mathrm{P}$, et al. Velocity and deformation imaging for the assessment of myocardial dysfunction. Eur J Echocardiogr 2009; 10:216-26.

13. Cook JR, Carta L, Galatioto J, et al. Cardiovascular manifestations in Marfan syndrome and related diseases; multiple genes causing similar phenotypes. Clin Genet 2015;87:11-20.

14. Huntgeburth M, Tiemann K, Shahverdyan R et al. Transforming Growth Factor b1 oppositely regulates the hypertrophic and contractile response to b-adrenergic stimulation in the heart. PLoS ONE 2011;6:e26628.

15. Matt P, Schoenhoff F, Habashi J, et al. GenTAC Consortium. Circulating transforming growth factor-beta in Marfan syndrome. Circulation 2009;120:526-32.

16. Hillebrand M, Millot N, Sheikhzadeh S, et al. Total serum transforming growth factor- $\beta 1$ is elevated in the entire spectrum of genetic aortic syndromes. Clin Cardiol 2014;37:672-9.

17. Svensson LG, Blackstone EH, Feng J, et al. Are MS and Marfanoid Patients Distinguishable on Long-Term Follow-Up? Ann Thorac Surg 2007;83:1067-74 